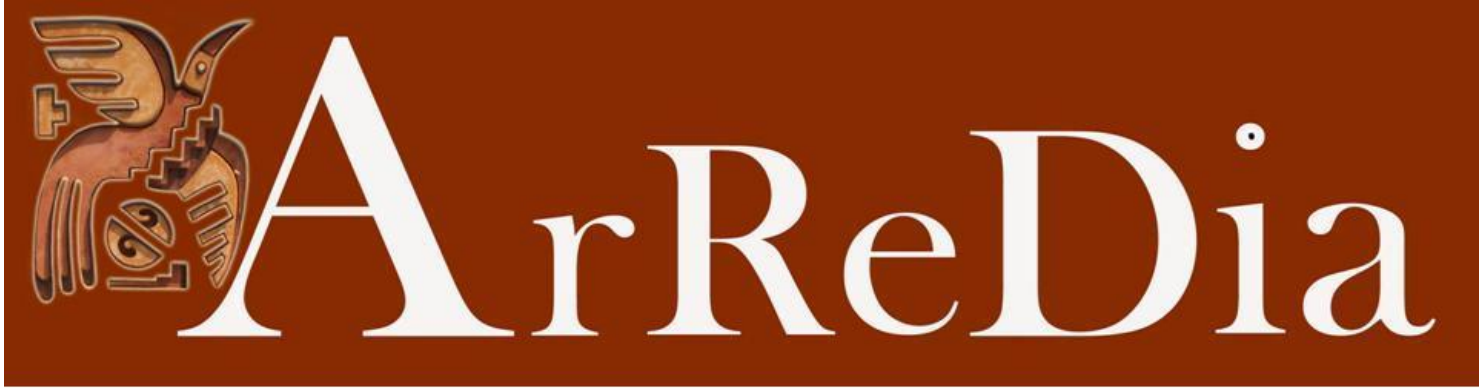

Revista da Faculdade de Comunicação, Artes e Letras / UFGD

\title{
O GROTESCO EM SHREK 2 (2004): UM OLHAR SEMIÓTICO
}

\author{
The Grotesque in Shrek 2 (2004): a semiotic look
}

\author{
Luiz Antonio Xavier Dias ${ }^{i}$ \\ Universidade Estadual do Norte do Paraná
}

\begin{abstract}
Resumo: A partir da base teórica pautada nos fundamentos semióticos de carnavalização e grotesco proposta por Bakhtin (1999; 1981; 2003; 1992) - neste artigo, apresentamos o resultado de pesquisa teórica que procurou investigar a noção de carnavalização do grotesco e também do riso em duas cenas enunciativas da obra cinematográfica Shrek 2 (2004). A animação da Dreamworks, teve sua inspiração na obra literária Shrek, seu maior mérito foi o de desconstruir personagens típicos como o ogro que se torna príncipe e uma princesa também ogra, tais fatos trouxeram grande mudança para o seguimento de animações digitais. A partir da descrição das cenas e do arcabouço teórico proposto pelo teórico russo, nosso objetivo foi de desvelar vários sentidos alicerçados no riso e no grotesco.
\end{abstract}

Palavras-chave: Carnavalização. Grotesco. Shrek 2 (2004).

\begin{abstract}
In this paper, we present the result of theoretical research that sought to investigate the notion of carnivalization of the grotesque and also of laughter in two Enunciative scenes of the cinematographic work Shrek 2 (2004). The animation of Dreamworks was inspired by the literary work Shrek, its greatest merit was to deconstruct typical characters such as the ogre who becomes prince and a princess also ogra, such facts brought great change to the follow-up of digital animations. From the description of the scenes and the theoretical framework proposed by the Russian theorist, our objective was to unveil several senses based on laughter and grotesque.
\end{abstract}

Keywords: Carnavalization. Grotesque. Shrek 2 (2004).

\section{Considerações Iniciais}

A animação digital atualmente é uma maneira dinâmica de se pensar no cinema e que tem atraído muito público para as telas da telona, muitas são as recriações tanto dos estúdios Disney, quanto Pixar ou Dreamworks para, com uma nova roupagem, capturar um número diverso de expectadores. Por sua vez Fossatti (2010; 2011) entende, assim como nós, que um filme de animação, dependendo do conteúdo temático, possibilita ao jovem um entretenimento seguro, destituído da sugestão e da personalização, enquanto, para os adultos, permite o retorno à inocência da juventude perdida, acrescida por uma profundidade temática, abstratamente representada.

Apresentada ao público no ano de 2004, a obra cinematográfica Shrek 2 (2004), filme que estamos analisando, desbancou concorrentes ao trazer para o mundo do cinema um herói que é um Ogro, uma princesa fora do convencional e um grande número de paródias carnavalescas para o seu enredo, conforme 
orienta Bakhtin (1999) o carnaval é o locus privilegiado da inversão, onde os marginalizados apropriam-se do centro simbólico, numa espécie de explosão de alteridade, onde se privilegia o marginal, o periférico, o excludente.

Nosso interesse ao estudar filmes de animação é que, segundo Vanoye e Goliot-Lété (1994, p. 55), um filme pode ser utilizado para se analisar uma sociedade, visto que ele oferece um conjunto de representações, as quais remetem à sociedade real, de modo direto ou indireto. Para uma interpretação sóciohistórica, a hipótese diretriz é a de que um filme sempre faz alusão ao presente, ao seu contexto de produção. No filme, "a sociedade não é propriamente mostrada, é encenada" (VANOYE; GOLIOT-LÉTÉ, 1994, p. 56).

Além disso, o cinema é, uma área que faz referência a muitas outras, como a pintura, escultura, música, portanto é transdisciplinar, para isso retomamos as palavras do mestre russo: "tudo o que é ideológico possui um valor semiótico (BAKHTIN/VOLOSHNOV, 1992, p.32). Semiótico é o que o cinema é em sua primeira impressão, na sua primeira forma de análise. Di Camargo Jr. (2009, p. 23) ressalta que ao analisar um filme, primeiro nos damos conta do caráter semiótico, mas:

\begin{abstract}
Somente após essa primeira absorção dessa realidade que vai ali se desenrolado e se desenvolvendo é que passamos a prestar atenção em detalhes e características mais dialógicas ou intertextuais que estas obras carregam implicitamente em si, como se fossem um código a ser decifrado por caçadores de enigmas, prontos a desvendar ali o seu gênero.
\end{abstract}

Nessa direção, entendemos a relevância dos estudos com um olhar semiótico uma vez que, segundo Santaella (1983):

\begin{abstract}
A Semiótica é a ciência que tem por objeto de investigação todas as linguagens possíveis, ou seja, que tem por objetivo o exame dos modos de constituição de todo e qualquer fenômeno como fenômeno de produção de significação e de sentido. (SANTAELLA, 1983, p 06)
\end{abstract}

O presente trabalho é, também, fruto de reflexões advindas da disciplina de Bases Semióticas da Visualidade ${ }^{1}$ do Programa de Pós-Graduação, strictu sensu em Comunicação da Universidade Estadual de Londrina, e, na presente pesquisa buscamos investigar a construção das significações que são desveladas a partir de duas cenas enunciativas da obra cinematográfica digital Shrek 2 (2004), a partir do constructo teórico bakhtiniano de carnavalização e grotesco.

O presente trabalho alicerça-se principalmente, como já posto, no conceito de carnavalização de Bakhtin, discutido na obra A cultura popular na Idade Média

\footnotetext{
${ }^{1}$ Disciplina ministrada pelo Professor Dr. Miguel Luiz Contani.
} 
e no Renascimento e em Problemas da poética de Dostoievski e em artigo teórico de Fiori e Contani (2014) cujo título é: Elementos argumentativos da carnavalização bakhtiniana na iconografia do heavy metal.

Ressalta-se que a presente pesquisa é bibliográfica e exploratória ou documental Mota-Roth (2010, p. 112). A metodologia envolve o procedimento de levantamento de bibliografia, já citado no referencial teórico, e documentos referentes sobre o problema em questão (como o conceito de carnavalização e o grotesco se manifestam em Shrek 2 (2004).

A partir do levantamento bibliográfico e dos suportes teóricos em análise, será feita uma pesquisa dedutiva Mota-Roth (2010), da teoria para os dados, e posteriormente uma verificação de vários sentidos produzidos por duas cenas enunciativas da obra cinematográfica em foco, bem como seus planos de câmera, cores, símbolos para que consigamos melhor compreender a constituição do grotesco na obra analisada.

O procedimento de análise proposto leva em consideração a retomada teórica dos conceitos bakhtinianos de carnavalização, riso, grotesco, na descrição de duas cenas enunciativas de Shrek 2 (2004) e, a partir de elementos da teoria cinematográfica, combinamos e expomos os sentidos produzidos na cena, tanto a partir da quebra de expectativa, quanto das disposições gráficas do contexto enunciativo.

\section{A animação digital: breves considerações}

A animação digital é formada pela convergência do cinema clássico e da computação. A relação entre as disciplinas criou a linguagem e influenciou o desenvolvimento de ambas. Desse modo, como a evolução da linguagem dos filmes e da tecnologia, a computação tem avançado graças às invenções dos pioneiros e inovações específicas.

A documentação histórica dos primórdios do gênero discursivo filme cinematográfico reconheceu a importância dos pioneiros da sétima arte e dos desenvolvimentos tecnológicos que modernizaram o meio. Da mesma forma, existem nomes familiares do início da animação digital, como John Whitney Jr., Edwin Catmull e Douglas Trumbull, que contribuíram para a adoção dos computadores na indústria cinematográfica (CHONG, 2011, p. 30,31).

Lucerna Júnior (2005) destacou que desde os primeiros momentos a animação digital alicerçou-se por meio da pesquisa, viabilizando novas possibilidades expressivas e firmando, dessa maneira, seu viés comercial. Além disso, os esforços para a formação e construção de personagens 3D tornaram-se importantes, em virtude de reduzirem o tempo de confecção dos projetos e o acabamento tornava-se cada vez melhor. 
Com o passar dos anos, em 1995 é lançado o primeiro filme de animação infantil digital Toy Story, em parceria com a Disney e Pixar Animation. Toy Story ganhou o óscar de melhor animação e inaugurou um novo campo de trabalho. A esse respeito, Dennis (2007, p. 192) afirma que com o 3D a animação muitas vezes quebra a expectativa de alguns ao pensar que se volta a uma estética realista, mas, ao contrário, voltam-se muitas vezes a tendências da década de 1950 do marco Disney, repetindo a fórmula mágica com uma cara nova: o 3D. O resultado da parceria entre Disney e Pixar tem sido caracterizado pelo sucesso de suas animações. Apresentando uma nova concepção de entretenimento, Pixar e Disney uniram as técnicas mais avançadas da computação gráfica à, imitar a realidade, antes só alcançada pela antiga e dispendiosa técnica da animação tradicional (COELHO et al, 2004).

Desse modo, Shrek 2 (2004) tem um elo fortíssimo com Walt Disney, visto que a produtora foi precursora dos desenhos animados. Sendo assim, também são importantes investigações para buscarmos respostas a muitos conteúdos temáticos e assuntos desses textos-enunciado de filmes.

No que diz respeito ao impacto da tecnologia digital no início do século XXI, Chong (2011) postula que isto tornou a produção e exibição de animação mais fácil do que nunca. Com uma fidelidade generalizada à Lei de Moore², as ferramentas disponíveis para os animadores estão cada vez mais sofisticadas e poderosas, produzindo imagens espetaculares e extraordinárias. Atualmente, a tecnologia incorporada e a padronização oferecem aos animadores iniciantes um caminho simples. A digitalização democratizou a produção de mídia. Câmeras digitais, música digital e a internet possibilitam que as ferramentas de produção estejam agora disponíveis em níveis domésticos. A animação digital está atingindo não só níveis máximos de desempenho como também ampliando sua aplicação, em síntese, ela é um tipo de leitura presente na modernidade mais contemporânea possível, segundo CHONG (2011).

\footnotetext{
2 Em 1965, Gordon Moore postulou uma observação a respeito da relação entre o custo unitário da produção de um circuito integrado, o número de transistores nesse circuito e o desenvolvimento com o passar do tempo, publicada na Revista Eletronics Magazine. A observação de Moore foi feita por meio do estudo empírico do potencial computacional dos primeiros computadores mecânicos, desde os anos 1930 até 1965, enquanto estava trabalhando na Intel. Em anos posteriores, essa observação foi chamada de lei pelo professor Carver Mead, do Califórnia Institute of Technology. Por extrapolação, Moore previu a duplicação no número de transistores em um circuito integrado a cada 18 meses, pelo menos até1975. Na realidade, tal previsão se manteve válida por mais três décadas e é esperado que se mantenha até os anos de 2020.
} 


\section{A carnavalização}

Para estudiosos alemães, carnaval significa lugar santo. Com efeito, Bakhtin busca esse sentido inicial, mas acrescenta a relevância das manifestações, e destaca a importância do riso e do grotesco (e suas manifestações com monstros, gestualidade licenciosa, banquetes orgiásticos, palhaços de todos os tipos, deformidades físicas, dentre outras) Bakhtin (1999, p.3-4, apud Fiore e Contani, 2014).

Bakhtin (1999) destaca a relevância da cultura oficial e dominante era a Igreja Católica e, além disso, explica que está ligada ao riso, ao humor e ao grotesco, além do destaque aos jargões, exposições de injúrias em praças públicas como essenciais para a formação da carnavalização.

Conforme apontam Fiore e Contani (2014),

a conjectura mais plausível a respeito da formação do termo carnaval, por ironia, é a que acusa a Igreja Católica Romana de proibir, aos fiéis, a fornicação e o consumo de carne durante os quarenta dias da Quadragésima ou Quaresma, em memória à permanência de Jesus Cristo no deserto, jejuando e sofrendo provações (FIORE E CONTANI, 2014, p. 41).

Segundo Bakhtin, uma das características dos festejos carnavalescos na Idade Média e no Renascimento é a inversão da hierarquia vigente: personalidades elevadas, como o rei, ganham sua versão rebaixada normalmente representada de maneira grotesca pelo Rei Momo. Por outro lado, o povo se permite imitar trajes e maneiras fidalgas. Portanto, o carnaval transmite uma impressão de mundo às avessas.

Com efeito, o carnaval provoca os exageros relacionados com o baixo corporal, a profusão de cores e detalhes e uma multidão compacta que sugere a mistura de corpos, características do grotesco. No carnaval, como na obra de Rabelais, o grotesco, associado ao riso alegre, adquire um sentido positivo. Neste filme da Dreamworks também, porque mesmo ironizando, satirizando e mostrando o grotesco, um dos intuitos do filme é a diversão.

\section{O grotesco}

Conforme apontam Fiore e Contani (2014, p. 40) “o termo grotesco encontra justamente sua gênese associada a esse sentido de algo recôndito e, em consequência, perturbador". A derivação de grotesco, por sua vez provém do substantivo grotta, que significa gruta. No século $\mathrm{XV}$, serve para designar estranhas decorações ou pinturas ornamentais descobertas em paredes subterrâneas das termas do imperador Tito, em Roma. 
Dessa maneira, são obras de arte que distorcem a ordem do mundo normal, expondo figuras surpreendentes em que formas vegetais, animais e humanas são misturadas com excepcional independência artística. As sociedades humanas constituídas de tom sério tendem a se sentir ultrajadas por manifestações dessa categoria estética (MOISÉS, 1984, p.266-267 apud Fiore e Contani 2014 p. 40). Com efeito, o grotesco, vem assumindo o significado de mau gosto, de defeituoso (mas não necessariamente de obsceno), de ridículo, de monstruoso e até de diabólico.

Assim, para Fiore e Contani (2014, p. 40) “a imagem grotesca bakhtiniana caracteriza-se pela versatilidade de transformação ou de metamorfose". Isso posto, entendemos pelas observações diacrônicas e pelas afirmações postas que tanto o grotesco, quanto a carnavalização estão presentes no filme de animação digital Shrek 2 (2004), uma vez que o mesmo é repleto de paródias que privilegiam o riso e o grotesco com o propósito de produzir no expectador sentimentos variados como a alegria e a quebra de expectativa.

\section{As cenas enunciativas}

Para Dias (2015), o enredo de Shrek 2 (2004), começa com a apresentação de um ogro, que após se casar com a Princesa Fiona viver feliz em seu pântano. Ao retornar de sua lua-de-mel, Fiona recebe uma carta de seus pais, não sabedores de que ela, agora, é um ogro ${ }^{3}$. Eles convidam o casal para um jantar na intenção de conhecer o marido da filha. Mais tarde no jantar o clima entre os pais de Fiona e Shrek está muito ruim. Shrek assim como em várias relações do nosso cotidiano tenta de toda forma impressionar o pai de Fiona, mas o rei se mostra preconceituoso com Shrek e o julga não por seu caráter, mas por sua beleza exterior.

Fiona muito triste é visitada por uma fada madrinha que simboliza características que muitas pessoas consideram como coisas fúteis (joias, dinheiro, pessoas bonitas, objetos caros), esse fato faz Fiona ter uma discussão com Shrek, desejando que ele se torne melhor e tenha um bom relacionamento com sua família.

Com muito custo, Fiona consegue convencer Shrek a ir visitá-los, tendo ainda a companhia do Burro. Porém, os problemas começam quando os pais de Fiona descobrem que ela não se casou com o Príncipe, a quem havia sido prometida, e enviam o Gato de Botas para separá-los.

Como podemos observar, o conteúdo temático - desvela que Shrek dialoga explicitamente com os contos de fadas, não apenas por retomarem o tema

\footnotetext{
${ }^{3}$ Para Chevalier (2012, p. 651) um ogro lembra os Gigantes, os Titãs. Simboliza a força cega e devoradora. Ele precisa de sua ração quotidiana de carne fresca, e o Pequeno Polegar engana-o facilmente, fazendo-o engolir suas próprias filhas. Entretanto, o ogro da história citada no filme é diferente, verde, bonzinho e amável.
} 
beleza, mas também por possuir todos os elementos inerentes a este gênero da esfera literária, elementos mágicos tais como como feitiços, princesas, rei, rainha, vilão, harmonia entre os personagens. Desse modo, podemos comparar Shrek 2 (2004) a A Bela e a Fera (1991), pois os dois apresentam temáticas parecidas, ao questionarem o valor real da beleza, por outro lado, os dois mantêm os elementos mágicos como princesas, seres da natureza falantes.

Entretanto, Shrek 2 (2004) tem chamado atenção por trazer uma nova concepção de beleza, por buscar demonstrar que sentimentos como amizade, companheirismo, bom caráter, podem fazer o amor florescer em qualquer pessoa, independentemente de sua beleza física. A história acontece na era medieval, apresentando castelos, cavaleiros com armaduras, torneio de lutas em arenas, entre outros elementos típicos dos contos de fadas.

O roteiro do filme foi pautado no livro Shrek, de Willian Steig (2001), sendo uma desconstrução do príncipe encantado. Num estilo desajeitado e nada gentil, a personagem principal faz o gênero de cara de malvado, todavia com um bom coração. De um jeito bem sutil, o filme nos traz a personagem que é feia e que tem a bondade dentro de si - algo que não foi enfatizado pelos contos de fada, que apontavam como más as personagens tidas como feias e, como boas pessoas, as personagens belas. Percebemos, inclusive, a temática da perseguição e exclusão por parte da sociedade em geral para com o protagonista.

Cabe destacar que, no cinema, o fato de muitas vezes as palavras serem substituídas por imagens, como se a plateia estivesse vendo a ação, sem a interferência de um narrador ou de sua voz, produz a impressão de que não há narração, mas apenas um processo de mostrar. No entanto, segundo as informações de Chatman (1992, apud COURSEUL 2003, p. 30) sobre o sistema narrativo no cinema, pode-se dizer que a presença do narrador se dá pela edição de imagens, reveladora da interferência do narrador na organização dos eventos da história. O termo narrador não está necessariamente associado a uma individualidade, contudo revela a presença de um agente organizador da diegese, isto é, da narrativa.

Em relação às condições de produção da obra cinematográfica Shrek 2 (2004), considera-se o filme como unidade significativa verbo-visual que mobiliza o discurso. Esse discurso angariou mais de 4.427.115 espectadores, de acordo com a Revista Cinema (jun/2007, p. 19).

A sua constituição deve-se a uma tecnologia avançada e três anos de dedicação por parte da equipe de produção. Segundo documentário presente nos recursos especiais (notas técnicas), o filme Shrek 2 foi produzido exclusivamente com a utilização de programas de informática. Desse modo, havendo uma preocupação com os movimentos faciais e os movimentos dos tecidos (roupas, cortinas), além de folhas, gramas etc. Aplicaram-se técnicas para os efeitos 
especiais como fluidos e chamas, além disso, a técnica de desenho computadorizado ainda não havia sido aplicada em personagens humanos.

A obra analisada traz diversos efeitos de humor, o mais recorrente é a paródia, que pode ganhar o sentido de uma imitação, uma subversão ao que já foi dito. Pela ótica de Sant'anna (1995), a paródia deforma o texto original, subvertendo sua estrutura de sentido inicial.

Ainda, para Bassols (2009, p 15, o filme Shrek 2, apresenta intertextualidade com 06 contos de fadas, são eles: Gato de Botas e Chapeuzinho Vermelho, de Charles Perrault (1697); Rei Sapo, dos Irmãos Grim (1812); Homem Biscoito, de Gengibre Revista St. Nicholas (1875), Pinóquio - Carlo Collodi (1881 a 1883) e Os Três Porquinhos - Joseph Jacobs (1890, todos contos de fadas referenciados por meio da paródia).

Esses intertextos podem ser feitos por meio de paráfrases ou paródias. De acordo com Bakhtin (1999), ao retomarmos o conceito de normalidade (centrípeta) e transformação (centrífuga) da língua, ou seja, as forças centrípetas atuam com vistas a normatizar, unificar e tornar homogênea a língua, ao passo que as forças centrífugas atuam no sentido de estratificar e tornar heterogênea a língua.

Desse modo, Hutcheon (1985, p. 85) defende que a paródia tanto pode ser centrípeta como centrífuga. Hutcheon traduz esse duplo sentido ao afirmar que "a paródia é normativa na sua identificação com o outro, mas é contestatória na sua necessidade edipiana de distinguir-se do outro anterior". Shrek 2 (2004) é um filme ao mesmo tempo homogeneizante e não normativo. No primeiro caso, mantêm, em sua estrutura narrativa, os mesmos elementos dos contos de fadas tradicionais: príncipe encantado, princesa, bruxa/ fada, cavalo branco, feitiço. No segundo, transgridem esses contos, pois o príncipe é um ogro; a princesa é horrorosa; o cavalo branco é um burro; e a fada madrinha, na verdade, é uma bruxa e o príncipe, que quer ficar com Fiona é bonito, mas malvado.

Ademais, a presença do humor é outro elemento que diferencia a narrativa em estudo dos demais contos de fadas. Para Corso:

\footnotetext{
A estrutura de Shrek mantém as principais características do conto de fadas tradicional: seguimos em um mundo mágico; temos um final resolutivo; realiza-se uma jornada de crescimento; há um ajudante mágico, ainda que atrapalhado; e tudo culmina na formação de uma família. A diferença é que essa jornada de crescimento agora será tanto externa como interna, e as personagens serão mais complexas, elas agora terão vida interior. Além disso acrescenta-se o humor (CORSO, 2006, p.178).
}

Desse modo, constatamos que tal recurso é de muita valia para o espectador, uma vez que chama sua atenção e faz relembrar acontecimentos 
passados, além do humor prender a atenção do espectador. Por intermédio da linguagem verbal ou audiovisual, ao contar essas histórias, Steig (2001) e Adamson (2004) ${ }^{4}$ reafirmam o papel do conto de fadas de "transmitir ao mesmo tempo significados manifestos e encobertos" e de "falar simultaneamente a todos os níveis da personalidade humana, comunicando de uma maneira que atinge a mente ingênua da criança tanto quanto a do adulto sofisticado" (BETTELHEIM, 1980, p. 14).

Em Shrek 2 (2004) há muitas paródias, mas, devido ao objeto do estudo não citaremos mais que uma, que é a passagem com o personagem Pinóquio, que ao tentar salvar Shrek quando está preso em um calabouço, está usando roupa íntima feminina. Assim como essa, Shrek 2 (2004) traz muitas passagens humorísticas. Pode-se citar também, dentre as cenas engraçadas o momento em que Fiona está fazendo sua barba com o seu amado Shrek, além dessa, há a paródia com o filme Homem Aranha, quando Fiona beija Shrek, que está em uma árvore.

Propp (1992) assinala que as condições para suscitar a comicidade são, primeiramente, a de que quem ri tem que ter pelo menos uma noção das exigências morais da natureza humana, algumas concepções do que seja justo e correto, e, por último, quando rimos é porque encontramos no mundo algo que contradiz o que consideramos certo dentro de nós, ou seja, algum defeito no mundo. "A contradição entre esses dois princípios é a condição fundamental, o alicerce para o nascimento da comicidade e do riso que dela se produz" (PROPP, 1992, p. 174).

Nesse sentido, Propp (1992) ressalta que o riso acontece quando as descobertas são inesperadas, a piada só é engraçada devido ao seu final inesperado e espirituoso, mas quando a ouvimos mais de uma vez, ela não é mais engraçada porque não há surpresa. Bakhtin (1999) explica a importância do riso ao justificar que no carnaval ou nos momentos carnavalescos precisamos apresentar nosso riso coletivo que se opõe ao tom sério e à solenidade repressiva da cultura oficial e do poder real e eclesiástico, mas que não se limita a ser negativo e destrutivo, antes projeta "o povo que ri em liberdade fecunda e regeneradora como a própria natureza". (SOERENSEN, 2011, p. 322).

A seguir, serão reproduzidos pequenos fotogramas representativos do filme e também a decupagem ${ }^{5}$ :

\footnotetext{
${ }^{4}$ Diretores de Shrek (2001) e Shrek 2 (2004).

${ }^{5}$ Em cinema audiovisual, decupagem é o planejamento da filmagem, a divisão de uma cena em planos e a previsão de como estes planos vão se ligar uns aos outros através de cortes. Especificamente, serão analisadas a posição da câmera, a voz dos personagens, a transcrição de suas falas e a significação a partir da constituição total da cena.
} 

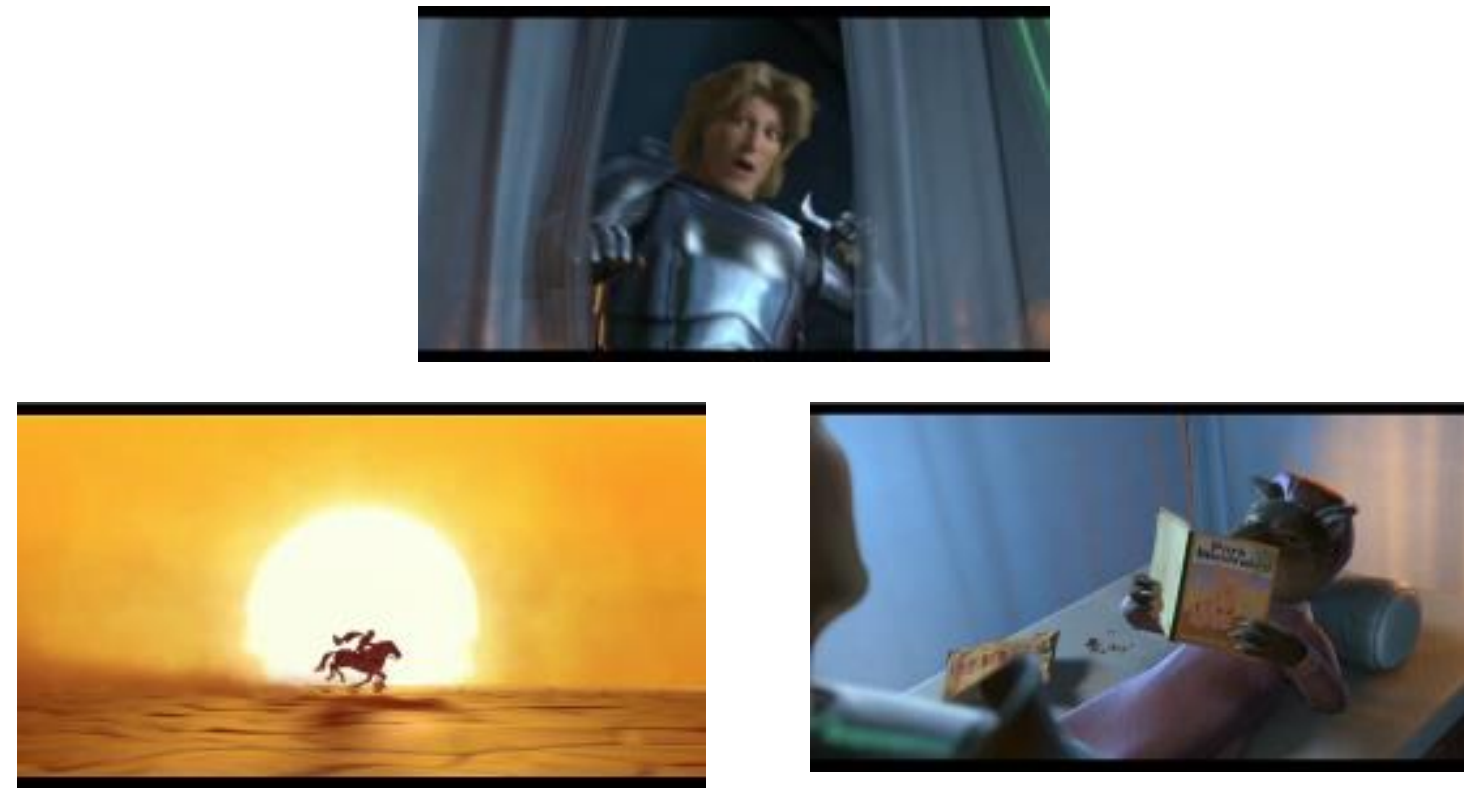

Imagem 1 - Frames 1 ao 3 - Shrek 2 (2004) - chegada de Encantado à masmorra de Fiona.

Sob o fundo musical romântico orquestrado, travelling vertical em plongée na tela preta acompanha um foco de luz que estaciona em um livro de aparência antiga. O livro se abre e suas folhas viram-se gradativamente, mostrando uma historia ilustrada enquanto uma voz off masculina lê o conteúdo do livro.

Voz masculina (off): “Era uma vez em um reino tão, tão distante um rei e uma rainha que foram abençoados com uma linda menininha e por toda a parte o povo era feliz, até o sol se pôr e eles virem que sua filha estava amaldiçoada por um terrível feitiço que acontecia todas as noites, desesperados procuraram a fada madrinha que os fizeram trancafiar a jovem princesa em uma torre em que ela esperaria pelo beijo de um príncipe encantado.

Som de cavalo trotando, câmera em travelling lateral, seria ele que enfrentaria a jornada através do frio cortante, do deserto escaldante para enfrentar um terrível dragão, pois ele era o mais corajoso e o mais belo .... enfrentaria um dragão e subiria na torre mais alta, do castelo mais alto câmera em plongée... close no rosto do príncipe encantado... desloca-se até o quarto da princesa, abre as cortinas e toma um susto... em close, no lugar da princesa está o lobo mau lendo uma história...

Príncipe encantado diz: Princesa Fiona?

Lobo mau: - nããão!!!

Encantando: Graças a Deus!!!!

Lobo mau: Ela está em lua de mel.

Encantado: - Mas onde?

(SHREK 2, PDI/DreamWorks, 2004).

No presente trecho, a partir das transcrições, percebemos que há a mistura do tempo verbal pretérito imperfeito do modo indicativo (era...) e também a utilização do futuro do pretérito (seria, atravessaria), para designar o personagem Encantado como uma possibilidade de ser salvador da princesa. No caso, o futuro do pretérito, também chamado de condicional, é usado para falar de um 
acontecimento futuro em relação a outro já ocorrido, fato que poderá ou não acontecer, algo incerto fazendo hipóteses ou suposições, surpresa ou indignação sobre um evento ou dar sugestões e fazer pedidos de maneira mais educada, ou seja, é apresentada uma possibilidade de Encantado encontrar sua princesa. Há, no entanto, uma quebra de expectativa do sujeito, nele, o expectador vai construindo uma imagem de que haverá um final feliz, marcada a noção do gênero discursivo, no caso, os contos de fadas terminam sempre com o príncipe encantando ficando com a mulher amada.

Todavia, o que constrói um novo efeito de sentido é justamente essa quebra de expectativa do espectador, na qual Encantado tentaria beijar a princesa e acaba se deparando com um lobo mau usando a roupa da vovó e lendo um livro de sua própria história. Para Propp (1992, p. 46), “a comicidade encontrase na correlação entre natureza física e espiritual, sendo que a primeira põe à mostra os defeitos do segundo, logo o corpo humano pode se tornar ridículo, constituindo o objeto risível". Conforme podemos observar, vários elementos grotescos estão presentes na quebra de expectativa, há a falta de convenção quando um príncipe vai procurar a sua amada, mas encontra um lobo mau, é essa alegria carnavalesca que Bakhtin (1999) expunha em suas obras e é desse momento que o riso funciona, ou seja, o inesperado forma o sentido da cena.

Na cena enunciativa analisada anteriormente, consideramos também a paródia por subversão, que é um dos princípios dialógicos apontados por Fiorin (2008) a qual atribui um novo sentido aos contos de fadas que já estavam cristalizados, isto é, o tema constrói uma significação na qual o ideal era que um príncipe encontrasse sua amada princesa, uma bela moça deitada em um leito, além disso, há a referência explícita a dois contos de fadas tradicionais $A$ bela adormecida e aos Três porquinhos, mas que, devido à inovação da obra, atribui-se um sentido inesperado no fio do discurso que acaba gerando o humor da cena.

Outro ponto relevante na construção de sentido temático é a relação das câmeras com a cena. No caso específico, elas se movimentam em travelling lateral, indicando o sofrimento de Encantado. Outro momento importante é que ao retirar uma parte da armadura de cavaleiro, Encantado deixa seus cabelos esvoaçarem, novamente o sentido de alguém esnobe confirma tal hipótese ideológica no decorrer do filme. Há também a mudança dos cenários, chuva, frio, desertos terríveis para que Encantado encontrasse sua princesa.

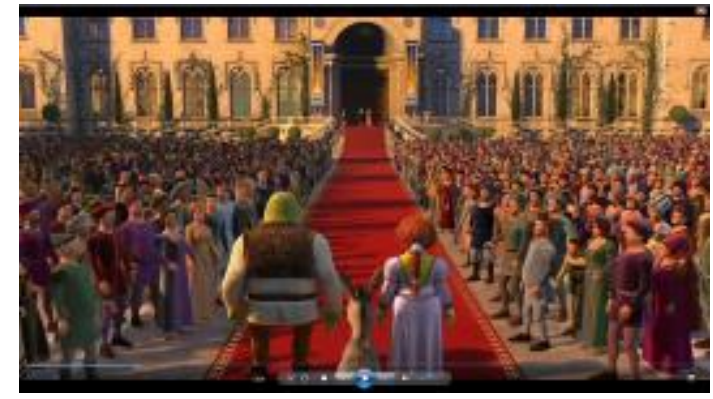



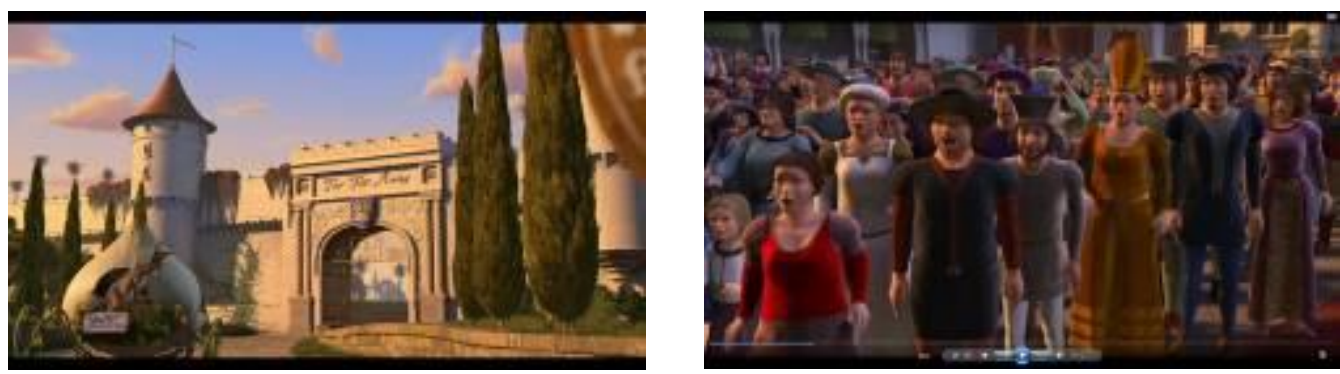

Imagem 2- Frames 4 ao 6 de Shrek 2 (2004) - A chegada do casal protagonista ao Reino.

A segunda cena analisada por nós é o momento em que Shrek e Fiona são convidados a se deslocarem ao palácio dos pais de Fiona para que o casal consiga uma bênção real, os dois se deslocam em uma carruagem durante alguns dias e o burro fiel também se desloca com o casal. No decorrer da viagem os três vão observando a paisagem e ao entrarem na cidade do Reino Tão, Tão Distante, inicia-se a trilha sonora da música Fukytown, da banda Lyps.

Tal trilha é animada e a tradução de sua letra sugere movimento, no refrão há as expressões traduzidas: "Preciso me mover para uma cidade"; "que é certa para mim"; "cidade que me mantenha em movimento"; "me mantenha dançando com alguma energia". Após o final da trilha, os três chegam à entrada do palácio e um servo anuncia: - Anuncio a tão esperada volta da linda princesa Fiona com seu novo marido. Close na abertura da trave da carruagem, libertamse pombas brancas e ao fundo aparece o casal de ogros, no quadro seguinte, a população se assusta e fala ahhhh. Aqui, constatamos o choque identitário com a palavra Bela, no caso porque o sentimento coletivo que se tem de belo é convencionado previamente, dessa maneira, os cidadãos ficam chocados, pois o belo para eles não é o mesmo que um belo Ogro ou Ogra.

Entendemos também que nessa cena há a presença novamente do grotesco, ou seja, a população de Tão, tão distante não esperava que saíssem da carruagem dois ogros herdeiros do trono, é aí que reside o grotesco bakhtiniano (1999) e o momento da carnavalização, ou melhor, o choque de realidade.

O que se pode constatar, na presente cena, é a convalidação do sentimento coletivo de decepção de toda a população e também dos pais, pois toda a cidade tinha um estereótipo de príncipe e princesa, mas o que acontece, na verdade é a aparição de dois ogros e um burro atrás das cortinas. Tais fatos podem ser comprovados pelos fotogramas 4 e 6, marcado pela expressão de decepção dos cidadãos de Tão Tão Distante...

Cabe destacar, ainda, na análise de um filme, o papel atribuído ao herói. Ele tem uma fundamental importância, pelo fato de que sem ele não há história. A personagem é tão necessária - até mais que o próprio narrador -, uma vez que sem ela e, também, sem o vilão, não existiriam conflitos e, consequentemente, a 
trama não aconteceria. Bakhtin (2003) assinalou a importância do herói na construção de sentido do texto:

[...] um autor modifica todas as particularidades de um herói, seus traços característicos, os episódios de sua vida, seus atos, pensamentos, sentimentos, do mesmo modo que, na vida, reagimos com um juízo de valor a todas as manifestações daqueles que nos rodeiam: na vida, todavia, nossas reações são díspares, são reações a manifestações isoladas e não ao todo do homem, e mesmo quando o determinamos enquanto todo, definindo-o como bom, mau, egoísta, etc., expressamos unicamente a posição que adotamos a respeito dele na prática cotidiana, e esse juízo o determina menos do que traduz o que esperamos dele (BAKHTIN, 2003, p. 25).

O herói, no caso, Shrek, vai salvar sua amada Fiona das mãos de um futuro noivo. Assim, torna-se dos mais importantes da trama, sem ele a história não teria acontecido, nem o conflito teria se desenrolado, ao menos começado, portanto, não haveria história. Nesse contexto, comprovamos sua importância por meio da canção "Holding Out for a Hero" (Esperando por um Herói), interpretada pela personagem Fada Madrinha, nos minutos finais do filme Shrek 2 (2004).

\section{Considerações Finais}

A animação digital atualmente já deixou de ser brincadeira de criança e tornou-se um grande nicho para a construção de cultura e propagação da mesma. Destaca-se a essa afirmação que uma cena cinematográfica, de animação digital ou não carrega consigo muitas significações e, a partir de um olhar crítico conseguimos entender muitas significações que nascem dessa profusão de manifestações artísticas em uma só obra de arte, tais manifestações podem ser destacadas como a música, a imagem, as falas dos personagens, que sozinhas não significam muito, mas, que a partir da combinação e da sutileza dos produtores geram novos sentidos.

A partir da premissa bakhtiniana de carnavalização, e grotesco, percebemos a partir desse pequeno corpus, constatamos que o filme Shrek 2 (2004) traz muitas significações, tanto o sentido de mudança produzido pelo diretor, gerado por meio da paródia. Cabe lembrar, que as marcas não verbais também remetem à construção de sentidos e a uma representação ideológica. Mais que fantasia, essa obra, além de resgatar sensações e emoções é um ótimo material linguístico discursivo para se trabalhar valores de uma sociedade estereotipada pela desconstrução desses valores já cristalizados e marcados. 


\section{Referências Bibliográficas}

BAKHTIN, Mikail. A cultura popular na Idade Média e no Renascimento: o contexto de François Rabelais. São Paulo: Hucitec, 1999.

Estética da criação verbal. 4. ed. São Paulo: Martins Fontes, 2003.

BAKHTIN, Mikail. (Volochinov). Marxismo e filosofia da linguagem. 6. ed. São Paulo: Hucitec, 1992.

Problemas da Poética de Dostoiévski. Trad. Paulo Bezerra. $1^{\mathrm{a}}$. ed. Rio de Janeiro: Forense Universitária, 1981.

BASSOLS, Pedro Inácio. Clássicos da literatura infantil revisitados em Shrek 2. Trabalho de Conclusão de Curso (Letras). UFRS - Universidade Federal do Rio Grande do Sul, 2009.

BETTELHEIM, Bruno. A psicanálise dos contos de fadas. Rio de Janeiro: Paz e Terra, 1980.

CHONG, Andrew. Animação digital. Porto Alegre: Bookman, 2011.

CORSO, D. L; CORSO, M. Fadas no divã: psicanálise nas histórias infantis. Porto Alegre: Artmed, 2006.

COURSEUIL, Anelise Reich. Literatura e Cinema. In: BONNICI, Thomas e ZOLIN, Lúcia Osana (org.). Teoria literária: abordagens históricas e tendências contemporâneas. 3. ed. rev. e ampl. Maringá: Eduem, 2009, p. 369-378.

COELHO, César; MAGALHÃES, Marcus; QUEIROZ, Aída; ZAGURY, Léa. Animation now! Madrid: Taschen, 2004.

DI CAMARGO JR, Ivo. O futuro analisado pela linguagem cinematográfica: diálogos entre a teoria do cinema e Mikhail Bakhtin. Dissertação de Mestrado. Programa de Pós-Graduação em Linguística da Universidade Federal de São Carlos UFSCar, São Carlos, 2009.

DIAS, Luiz Antonio Xavier. Gênero discursivo filme de animação infantil: práticas discursivas e ação docente para o multiletramento. 2015 . 232 f. Dissertação (Mestrado) Programa de Pós-graduação em Estudos da Linguagem Universidade Estadual de Londrina, Londrina-PR, 2015.

FIORE, Adriano Alves; CONTANI, Miguel Luiz. Elementos argumentativos da carnavalização bakhtiniana na iconografia do heavy metal. Bakhtiniana: Revista de Estudos do Discurso, v. 9, p. 35-52, 2014.

FIORIN, José Luiz. Introdução ao pensamento de Bakhtin. São Paulo: Ática, 2008. 
FOSSATTI, Carolina Lanner Categorias de narratividade no cinema de animação: atualização dos valores éticos de Aristóteles segundo Edgar Morin. Tese de Doutorado. Programa de Pós-graduação em Comunicação Social. Pontifícia Universidade Católica do Rio Grande do Sul. PUC/RS, 2010. 409 p.

Cinema de animação: um diálogo ético no mundo encantado das histórias infantis. Porto Alegre: Sulina, 2011.

HUTCHEON, Linda. Uma teoria da paródia: ensinamentos das formas de arte do século XX. Lisboa: Edições 70, 1985.

LUCENA JÚNIOR, Alberto. Arte da animação: técnica e estética através da história. São Paulo: Senac, 2005.

MORENO, Anônio. A experiência brasileira no cinema de animação. Rio de Janeiro: Artenova, 1979.

MOTTA-ROTTH, Desirée; HANDGES, Graciela Rabuske. Produção textual na universidade. São Paulo: Parábola Editorial, 2010.

PROPP, Vladimir I. Comicidade e riso. São Paulo: Ática, 1992.

SANTAELLA, Lúcia. O que é semiótica. São Paulo: Brasiliense, 1983.

SOERENSEN, Claudiana. A carnavalização e o riso segundo Mikhail Bakhtin. Travessias (UNIOESTE. Online), v. 11, p. 318-331, 2011.

STEIG, Wilian. Shrek! Trad. Eduardo Brandao. São Paulo: Companhia das Letrinhas, 2001. Não paginado.

VANOYE, Francis.; GOLIOT-LETE, Anne. Ensaio sobre a análise fílmica. Trad. Marina Appenzeller. Campinas: Papirus, 2006.

XAVIER, Ismail. O discurso cinematográfico: a opacidade e a transparência. São Paulo: Paz e Terra, 1983.

Filmografia

SHREK. Direção: Andrew Adamson e Vicky Jenson. Produção: PDI/DreamWorks, 2001. 1 DVD (93 min.), widescreen, color

SHREK 2. Direção: Andrew Adamson. Produção: Jeffrey Katzenberg; Aron Warner. Califórnia: DreamsWorks Animation, 2004, 1 DVD (105 min.) son., color. 
i E-mail do autor: laxdias@uenp.edu.br 